Ethylene

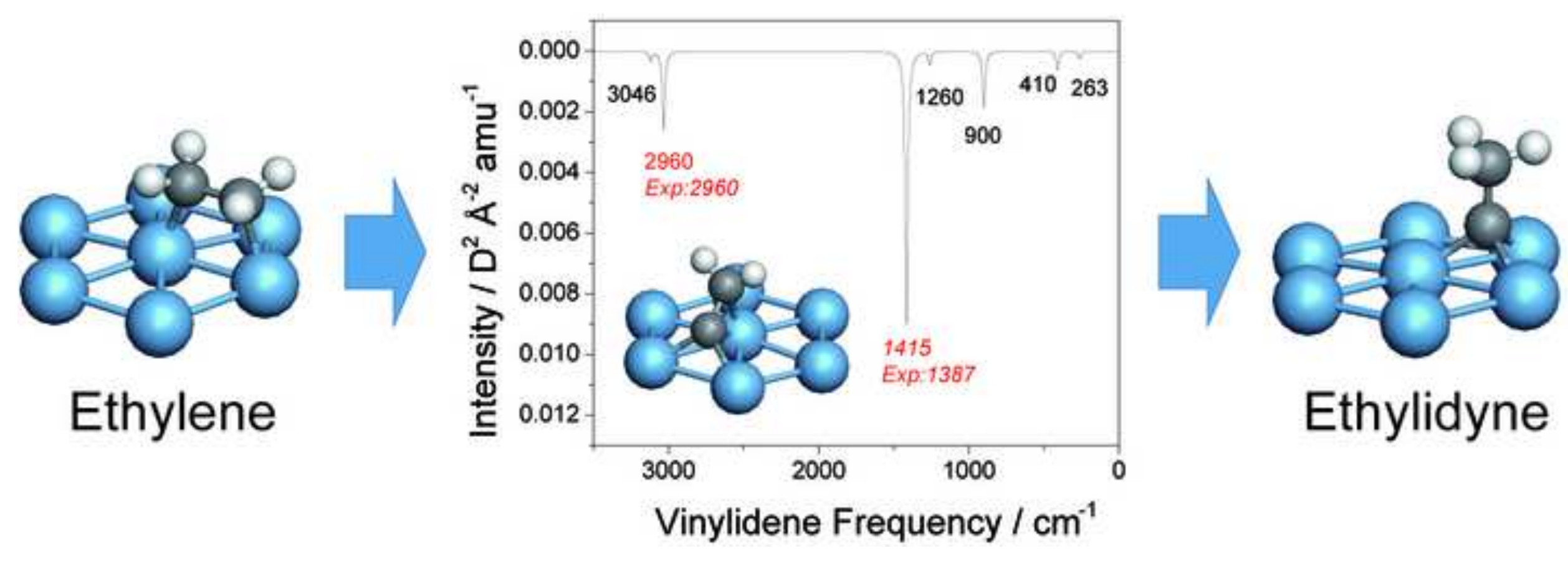

Vinylidene Frequency $/ \mathrm{cm}^{-1}$

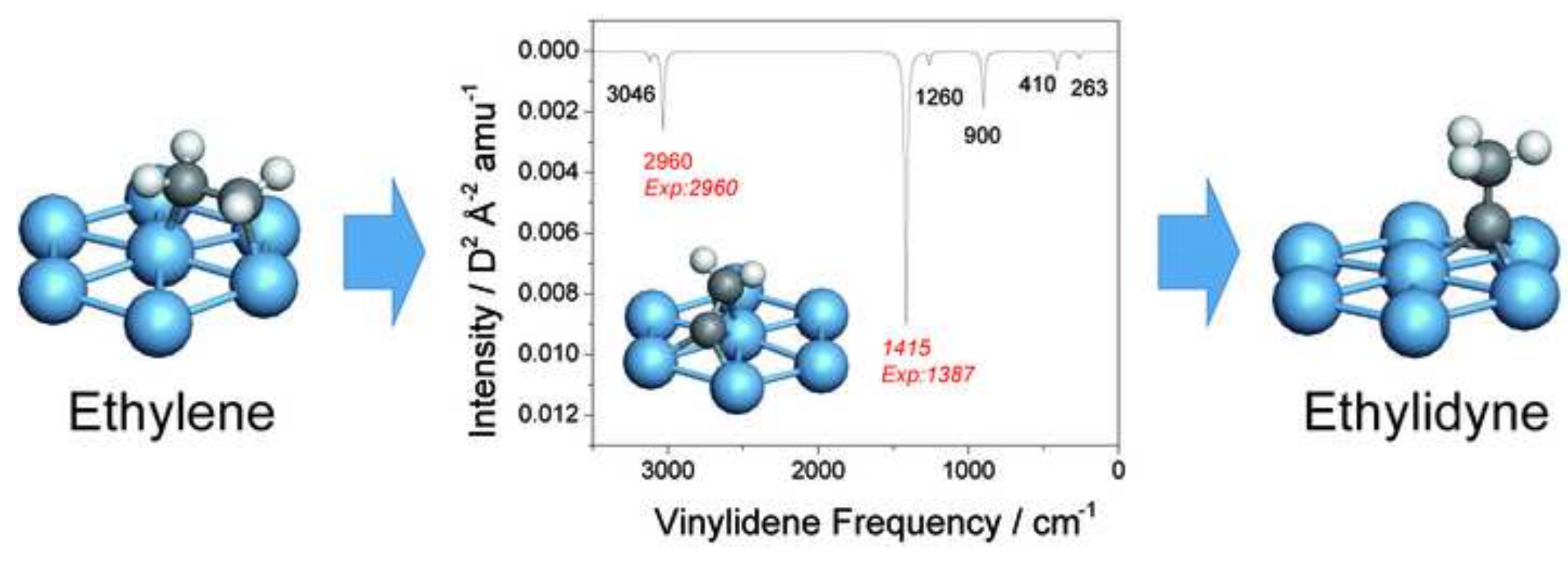

Ethylidyne

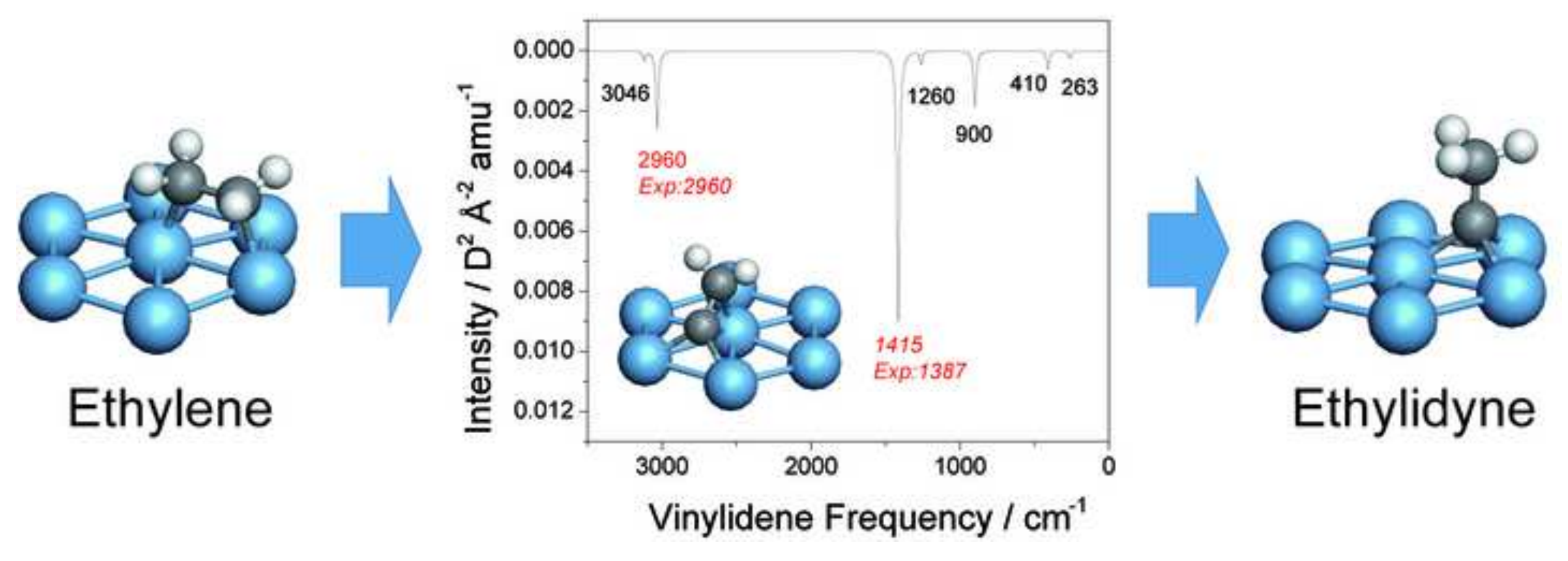




\title{
Identification of surface intermediates during ethylidyne formation on Pt(111) by calculation of infrared intensities and deuterium isotope shifts
}

\author{
Zhi-Jian Zhao, Jeffrey P. Greeley* \\ School of Chemical Engineering, Purdue University, West Lafayette, IN 47907
}

\begin{abstract}
The conversion of ethylene to ethylidyne on $\mathrm{Pt}(111)$ is a well-studied model reaction related to conversion of hydrocarbons over noble metal catalysts. For this chemistry, a two step mechanism that proceeds via an ethylidene intermediate has been generally accepted since the mid-1990s. However, recent DFT calculations (J. Phys Chem. C 2010, 114, 12190) have suggested that this intermediate may, in fact, be short-lived and should not be observed. Experimental verification of this prediction, though, is not straightforward, and to provide further theoretical results by which the prediction could be more easily evaluated, we present a set of benchmark calculations of infrared frequencies and intensities of candidate intermediates adsorbed on the $\operatorname{Pt}(111)$ surface at realistic coadsorbate coverages. The results show that only modest differences in frequencies and intensities exist between these intermediates, rendering direct spectroscopic differentiation difficult. However, by substituting the $\mathrm{C}_{2}$ species and intermediates with deuterium, it is shown that one characteristic vibrational band of vinylidene and ethylidene can be separated by well over $100 \mathrm{~cm}^{-1}$. This result provides a clear prediction that, if coupled with measured vibrational spectra of deuterium-labeled $\mathrm{C}_{2}$ species, could definitively differentiate between the most likely intermediates in this reaction network.
\end{abstract}

\section{Keywords}

Density functional theory, adsorption, hydrogenation catalysts, ethylidyne, $\operatorname{Pt}(111)$, infrared spectroscopy

\footnotetext{
To whom correspondence should be addressed. Email: jgreeley@purdue.edu, Fax: +1 (765) 494-0805, Tel: +1 (765) 494-1282
} 


\section{Introduction}

The study of the chemistry of hydrocarbons over noble metal catalysts is essential to improve the activity and selectivity of many important catalytic processes in the petrochemical industry. A well-studied model reaction in this regard is the conversion of ethylene on transition metal surfaces[1-4]. On $\mathrm{Pt}(111)$, in particular, an important conclusion from these studies is that two types of adsorption configurations are possible for ethylene: a $\pi$-adsorbed species at very low temperatures and in certain coadsorbed systems[5], and a di- $\sigma$ bonded species at temperatures higher than $52 \mathrm{~K}[6]$. An additional conclusion is that, under UHV conditions, further heating of the system will irreversibly convert ethylene to ethylidyne, $\mathrm{CH}_{3}-\mathrm{C} \equiv$, which is the only stable surface species at room temperature[7]. $\mathrm{C}-\mathrm{C}$ bond breaking of the $\mathrm{C}_{2}$ species is, in turn, believed to take place at even higher temperatures, with coke formation at temperatures higher than $500 \mathrm{~K}[8]$.

The exact mechanism of the conversion of ethylene to ethylidyne has long been debated. Nearly all of the $\mathrm{C}_{2}$ species, including vinyl $\left(\mathrm{CH}_{2} \mathrm{CH}\right)$, vinylidene $\left(\mathrm{CH}_{2} \mathrm{C}\right)$, ethylidene $\left(\mathrm{CH}_{3} \mathrm{CH}\right)$, and ethyl $\left(\mathrm{CH}_{3} \mathrm{CH}_{2}\right)$, have been proposed as intermediates during this transformation. However, based on extensive kinetic and surface spectroscopy studies, a generally accepted mechanism involving an intermediate ethylidene species gradually emerged[9-12]. This mechanism involved a 1,2 $\mathrm{H}$-shift reaction from ethylene to form ethylidene, followed by a dehydrogenation step to form ethylidyne. The second dehydrogenation step was assumed to be rate-determining in order to fit available experimental results on this system.

Recent theoretical studies[1,13] on this system have pointed to a different mechanistic interpretation. The associated DFT calculations showed a high barrier, over $1.5 \mathrm{eV}$, for the direct 1,2 H-shift reaction on $\mathrm{Pt}(111)$. Similarly high $\mathrm{H}$-shift barriers were observed on $\operatorname{Pt}(110)[14,15]$. In addition, the dehydrogenation barrier from ethylidene to ethylidyne was found to be very low[1], indicating that any ethylidene that does form will be only shortlived. Further, kinetic Monte Carlo simulations based on these results[13] clearly showed that adsorbed vinylidene can be present at non-negligible coverages during ethylene conversion. A three-step mechanism which only involves hydrogenation-dehydrogenation reactions, ethylene $\rightarrow$ vinyl $\rightarrow$ vinylidene $\rightarrow$ ethylidyne, was proposed based on these kMC results[13].

In order to provide further theoretical predictions that, when coupled with experiments, could help to conclusively identify the key intermediates in this reaction network, we present a series of benchmark calculations of the vibrational spectra of the various reactants and possible intermediates on $\operatorname{Pt}(111)$ at realistic coadsorbate coverages. Both frequencies and infrared intensities are determined and, by performing additional calculations of spectra for 
deuterium-substituted $\mathrm{C}_{2}$ intermediates, it is shown that one characteristic vibrational band for vinylidene can be clearly separated from those of the other adsorbates. When coupled with experiments on deuterium-substituted $\mathrm{C}_{2}$ species, these predictions could conclusively identify the crucial intermediates in this chemistry.

\section{Computational Details}

The calculations are carried out with the plane-wave based Vienna Ab-initio Simulation Package (VASP)[16,17]. The generalized-gradient approximation (GGA), in the form of the exchange-correlation functional PW91, is employed[18]. The interaction between atomic cores and electrons is described by the projector augmented wave (PAW) method[19,20]. The ideal $\mathrm{Pt}(111)$ surface is modeled by periodic five-layer slabs repeated in a supercell geometry with at least $2.5 \mathrm{~nm}$ vacuum spacing between slabs. The equilibrium structures are taken from previously published calculations[1]. To obtain the vibrational frequencies, a normal mode analysis, where the elements of the Hessian were approximated as finite differences of gradients, is carried out, with positive and negative displacements of $0.015 \AA$ along each Cartesian direction. A $5 \times 5 \times 1 k$ point grid, together with Fermi broadening with a width of $0.1 \mathrm{eV}$, are employed. The valence wave functions are expanded in a planewave basis with a cutoff energy of $520 \mathrm{eV}$, with the SCF energy convergence set to $10^{-7} \mathrm{eV}$.

Calculated harmonic frequencies for $\mathrm{C}-\mathrm{H}$ stretching modes are generally too high to be directly compared with experiments, in view of the strong anharmonicity effects associated with these modes. A simple, and widely used, method to improve the comparison is via a scaling factor, obtained by comparing suitable calculated and experimental values[21]. A factor of $0.976 \pm 0.012$ was obtained in our previous study[22], which is very close to the value, 0.969 , based on values determined in another study of propylene and propylidyne chemistry over $\mathrm{Pt}(111)[23]$. In the present work, the reported $\mathrm{C}-\mathrm{H}$ stretching frequencies are scaled by this value, but we did not apply scaling to the other type of modes, including C-D stretching modes, since these frequencies compare well with available experimental observations[24] (differences of less than $30 \mathrm{~cm}^{-1}$ for C-D stretching modes, as shown in Table 3).

The infrared intensities can be calculated from a finite difference approximation of the gradient of the dipole moment[23]. According to the metal surface selection rule, only the vibrational modes that significantly change the dipole moment in the direction perpendicular to the surface have noticeable intensity. The change of the dipole moment parallel to the surface will be cancelled out by the induced metal surface dipole moment. Thus, in our analyses, we use the $z$ component (perpendicular to metal surface) of the dipole moment to represent the total electric dipole of the system. In order to rigorously converge the absolute value of the surface dipole, the vacuum spacing between slabs was increased to greater than 
$2.5 \mathrm{~nm}$ and the VASP dipole correction was applied to the potential and forces. The finite difference analyses were performed by displacing the adsorbate along each normal mode vector with a scaled vector length determined by the following equation:

$$
I_{i}^{I R} \propto\left|\frac{d \boldsymbol{\mu}}{d Q_{i}}\right|^{2}=\left|\frac{\boldsymbol{\mu}_{z}\left(Q+k Q_{i}\right)-\boldsymbol{\mu}_{z}\left(Q-k Q_{i}\right)}{2 k Q_{i}}\right|^{2}
$$

where $\boldsymbol{\mu}$ is the electric dipole moment of the system, $\boldsymbol{\mu}_{z}$ is the $z$ component of the system dipole, $Q$ is the equilibrium coordinate, $Q_{i}$ is the $i$ th normal-mode coordinate, and $k$ is a scale factor, related to the chosen step size, which is set at 0.1 in our calculations.

\section{Results and Discussion}

During the conversion of ethylene over $\mathrm{Pt}(111)$, the most abundant surface species are ethylene and ethylidyne, depending upon the temperature. In this section, we begin by describing the simulated spectra of these abundant and easily identified surface species, and we verify the accuracy of our method by comparing the calculated intensity with experimental values recently reported by Deng et al.[8] Then, we turn to a discussion of the simulated spectra of the short-lived surface intermediates, including vinyl, vinylidene and ethylidene, in both non-deuterated and deuterated forms, and we compare the predicted spectra with experimentally observed spectra to determine the most relevant intermediates for this chemistry.

\subsection{Spectra of $\mathrm{C}_{2} \mathrm{H}_{\mathrm{x}}$ surface species at saturated coverage}

Ethylidyne $\mathbf{C C H}_{3}$. The optimized structure of ethylidyne is shown in Fig. 1. The most stable adsorption site for ethylidyne on $\mathrm{Pt}(111)$ is fcc, as determined by both LEED studies[25] and previous DFT calculations[1,26]. We will focus on the result at $1 / 3 \mathrm{ML}$ since this was reported to be the saturation coverage on similar metal surfaces[13]. Due to the perpendicularly bonded nature of ethylidyne, several intense peaks are observed on the surface (Fig. 2a, Table 1). The most intense such peak is $\mathrm{CH}_{3}$ symmetric bending (umbrella) at $1325 \mathrm{~cm}^{-1}$, followed by $\mathrm{CH}_{3}$ symmetric stretching at $2871 \mathrm{~cm}^{-1}$ and $\mathrm{C}-\mathrm{C}$ stretching at 1107 $\mathrm{cm}^{-1}$. The intensity of the latter two modes is about $65 \%$ of the intensity of the $\mathrm{CH}_{3}$ symmetric bend. All three modes are quite close to the experimentally reported frequencies: 1340, 2887 and $1124 \mathrm{~cm}^{-1}$, respectively. The intensities of the other peaks are less than $3 \%$ of the intensity of the $\mathrm{CH}_{3}$ symmetric bending peak. The calculated and experimental frequencies of these other peaks are also in good agreement, including $\mathrm{CH}_{3}$ asymmetric bending (calculated 2943, 2938; experimental $2939 \mathrm{~cm}^{-1}$ ), $\mathrm{CH}_{3}$ asymmetric bending (calculated 1406, 1407; experimental $1444 \mathrm{~cm}^{-1}$ ), and $\mathrm{CH}_{3}$ symmetric rocking (calculated 961, 962; experimental $975 \mathrm{~cm}^{-1}$ ).

di- $\sigma$ Ethylene $\boldsymbol{C H}_{2} \boldsymbol{C H}_{2}$. There are two modes for ethylene adsorption on $\operatorname{Pt}(111)$ : $\pi$ 
adsorption with both $\mathrm{C}$ atoms attached to the same top site of one Pt atom via a $\pi$ donor bond, and a di- $\sigma$ mode with two $\mathrm{C}$ atoms attached to two adjacent $\mathrm{Pt}$ atoms at a bridge site in $\eta^{2}$ fashion. Experimental studies have shown that $\pi$-bound ethylene is only stable at low temperatures, and it will convert to the di- $\sigma$ mode above $52 \mathrm{~K}[6]$. In the following, therefore, we will focus on the discussion on the calculated spectra of di- $\sigma$ ethylene since our reference experimental value was measured at $85 \mathrm{~K}$. The saturation coverage of ethylene has been reported to be 1/4 ML on $\mathrm{Pt}(111)$ [13], and our analysis is performed at this coverage. Unlike ethylidyne, di- $\sigma$ ethylene is adsorbed in flat configuration on $\operatorname{Pt}(111)$ (Fig. 1), leading to weaker IR signals due to the surface selection rules (Fig. 2b, Table 1). However, the $\mathrm{sp}^{3}$ hybridized nature of di- $\sigma$ ethylene causes the $\mathrm{CH}_{2}$ groups to be slightly bent away from the Pt surface instead of parallel to $\mathrm{Pt}(111)$, which leads to an intense peak for the $\mathrm{CH}_{2}$ symmetric stretching mode, located at $2913 \mathrm{~cm}^{-1}$ by DFT calculations. The other modes, which have moderate intensities, include $\mathrm{CH}_{2}$ scissoring at $1419 \mathrm{~cm}^{-1}$ and a mixture of $\mathrm{CH}_{2}$ wagging and C-C stretching at 1036 and $981 \mathrm{~cm}^{-1}$. The location of these modes are all very close to the experimentally reported values, at 2908, 1416, 1042, and $995 \mathrm{~cm}^{-1}$, respectively. However, the DFT-predicted intensity of the latter two modes is about $20 \%$ of the most intense mode $\left(\mathrm{CH}_{2}\right.$ symmetric stretching), which is somewhat stronger than the corresponding peak intensities reported in Ref 8.

Other intermediates. The above results indicate that the DFT calculations succesfully reproduce experimental IR spectra for stable $C_{2}$ specices on $\mathrm{Pt}(111)$. In the following, we turn to a description of the simulated spectra of the various surface intermediates, including vinyl, vinylidene and ethylidene. All of the spectra are simulated at 1/3 ML, which is the same as the considered ethylidyne coverage. To our knowledge, there are no directly measured spectra for these intermediates on the $\mathrm{Pt}(111)$ surface due to the unstable nature of the species.

Vinyl $\mathrm{CHCH}_{2}$. The most stable adsorption site for vinyl is fcc on $\mathrm{Pt}(111)$. Compared to ethylene, the tilted vinyl molecule (Fig. 1) has more IR active modes (Fig 3a, Table 2). The most intense mode is $\mathrm{CH}_{2}$ symmetric stretching at $2880 \mathrm{~cm}^{-1}$. The next two most intense modes include the symmetric mixture of $\mathrm{CH}_{2}$ wagging and $\mathrm{CH}$ in-plane bending at $954 \mathrm{~cm}^{-1}$ and $\mathrm{CH}$ stretching at $2932 \mathrm{~cm}^{-1}$. The other, less intense, peaks include $\mathrm{CH}_{2}$ symmetric stretching at $3014 \mathrm{~cm}^{-1}, \mathrm{CH}_{2}$ scissoring at $1385 \mathrm{~cm}^{-1}$, and a mixture of $\mathrm{CH}$ in-plane bending and C-C stretching at 1107 and $1062 \mathrm{~cm}^{-1}$.

Vinylidene $\mathrm{CCH}_{2}$. The adsorption of vinylidene is similar to vinyl, also preferring to bind at a threefold site (Fig. 1). However, the C-C bond is more tilted away from the surface compared to the vinyl case. As shown in Fig. $3 \mathrm{~b}$ and Table 2, the most intense mode is the $\mathrm{CH}_{2}$ scissoring mode, and the second most intense mode is $\mathrm{CH}_{2}$ symmetric stretching. 
Several other IR active peaks include $\mathrm{CH}_{2}$ asymmetric stretching at $3046 \mathrm{~cm}^{-1}$, C-C stretching at $1260 \mathrm{~cm}^{-1}$, and $\mathrm{CH}_{2}$ rocking at $900 \mathrm{~cm}^{-1}$.

Ethylidene $\mathrm{CHCH}_{3}$. Ethylidene prefers to bind at bridge sites of $\operatorname{Pt}(111)$ in a $\mu$ fashion (Fig. 1). As is the case with vinyl, we observed a series of intense peaks for ethylidene (Fig 3c, Table 2). The most intense such peak is $\mathrm{CH}_{3}$ symmetric stretching at $2863 \mathrm{~cm}^{-1}$. There are three other modes which have at least half of the intensity of the strongest mode, including $\mathrm{CH}_{3}$ asymmetric bending at $1403 \mathrm{~cm}^{-1}$, a mixture of $\mathrm{CH}$ in-plane bending and $\mathrm{CH}_{3}$ symmetric rocking at $1245 \mathrm{~cm}^{-1}$, and C-C stretching at $1048 \mathrm{~cm}^{-1}$.

\subsection{Spectra of $C_{2} D_{x}$ surface species at saturated coverage}

A common technique to assist in the assignment of vibrational peaks is to substitute atoms with isotopically labeled equivalents. Isotopic substitution does not change the electronic structure of the system. However, it does affect the reduced mass of the normal modes. In general, heavier atoms increase the reduced mass, which leads to a red shift of the corresponding modes. As we show below, substitution of the hydrogen atoms in ethylene with deuterium induces frequency shifts in the intermediates that, when coupled with appropriate experiments, could lead to conclusive identification of the relevant intermediates.

By comparing with experimental spectra of $\mathrm{C}_{2} \mathrm{D}_{4}$ and $\mathrm{CCD}_{3}$ adsorbed on $\mathrm{Pt}(111)$ (Table 3)[5], we observed that, for C-D stretching modes, the anharmonic effect is not as strong as it is for $\mathrm{C}-\mathrm{H}$ stretching modes, and the difference between the calculated and experimental values is less than $30 \mathrm{~cm}^{-1}$. Thus, we do not scale the calculated values for the surface-adsorbed species. The stretching modes shift from $\sim 3000 \mathrm{~cm}^{-1}$ in adsorbed $\mathrm{C}_{2} \mathrm{H}_{\mathrm{x}}$ (Tables 1 and 2, Figs. 2 and 3) to $2100-2300 \mathrm{~cm}^{-1}$ in adsorbed $C_{2} D_{x}$ (Tables 3 and 4, Figs. 4 and 5). The calculated intensities are larger for the symmetric C-D stretching modes than for the corresponding asymmetric modes. This result is quite understandable, since in general the symmetric vibrations will cause larger changes in the surface dipole perpendicular to the Pt surface.

The substituted $\mathrm{D}$ atoms also have strong isotope effect on the bending modes of $\mathrm{CD}_{\mathrm{x}}$ groups. In the $\mathrm{C}_{2} \mathrm{H}_{\mathrm{x}}$ case, the bending modes have frequencies that span a large range between $\sim 450$ and $1400 \mathrm{~cm}^{-1}$ (Tables 1 and 2, Figs. 2 and 3). This range shifts downwards, to about $400-1050 \mathrm{~cm}^{-1}$, in the case of $C_{2} D_{x}$ (Tables 3 and 4, Figs. 4 and 5). This range is at least $100 \mathrm{~cm}^{-1}$ lower than the $\mathrm{C}-\mathrm{C}$ stretching modes of $\mathrm{C}_{2} \mathrm{D}_{\mathrm{x}}$, and we do not observe obvious mixing between the bending modes and $\mathrm{C}-\mathrm{C}$ stretching modes in case of $\mathrm{C}_{2} \mathrm{D}_{\mathrm{x}}$. More interestingly, all of the $\mathrm{C}-\mathrm{C}$ stretching modes are now located in a narrow range between 1110 and $1139 \mathrm{~cm}^{-1}$ with the exception of $\mathrm{CCD}_{2}$. In the latter case, the $\mathrm{C}-\mathrm{C}$ bond is stronger than in the other cases, which is reflected by the almost $200 \mathrm{~cm}^{-1}$ higher frequency of C-C 
stretching and about $0.08 \AA$ shorter C-C bond length.

\subsection{Identification of observed intermediate during ethylidyne formation}

Previous studies[8,27] reported two intense modes which were related to the intermediate formed during ethylene conversion to ethylidyne: one $\mathrm{CH}$ stretching mode at $2957-2960 \mathrm{~cm}^{-}$ 1 , and one bending mode at $1387 \mathrm{~cm}^{-1}$. These modes were assigned to ethylidene in both studies. Evidence for this assignment came from comparison with an organometallic complex, $\mathrm{Os}_{2}(\mathrm{CO})_{8}\left(\mathrm{CHCH}_{3}\right)[28]$, which also shows similar vibrational modes at $2950 \mathrm{~cm}^{-1}$ and $1369 \mathrm{~cm}^{-1}$. Moreover, there is evidence from vibrational spectroscopy of intermediates resulting from decomposition of 1,1-diiodeothane on $\operatorname{Pt}(111)$ [29]. The corresponding features reported at $2972 \mathrm{~cm}^{-1}$ and $1372 \mathrm{~cm}^{-1}$ were assigned to ethylidene formed after dissociation of C-I bonds. These studies provide plausible evidence in support of the role of ethylidene as an intermediate in ethylene conversion to ethylidyne.

In contrast to the above picture, previous DFT calculations showed a very low barrier, less than $30 \mathrm{~kJ} \mathrm{~mol}^{-1}$, for dehydrogenation of ethylidene, indicating that, even if some ethylidene could form on the Pt(111) surface, it would have a very short lifetime and would not be spectroscopically observable[1]. Moreover, both ethylidene and vinylidene can be directly formed via vinyl. The calculated barrier to form vinylidene is $4-25 \mathrm{~kJ} \mathrm{~mol}^{-1}$ lower than ethylidene at different coverages, which suggests favorable selectivity towards vinylidene. Further, the hydrogenation of vinylidene has a barrier in the range of 58-80 kJ $\mathrm{mol}^{-1}$, and this higher barrier could lead to slower hydrogenation of vinylidene and consequent higher coverage on the surface. Indeed, kMC simulations based on these DFT energies[13] show accumulation of vinylidene instead of ethylidene during ethylene conversion.

The calculated vibrational spectra in the present work demonstrate that vinylidene is also a good candidate for the observed intermediate. As mentioned above, multiple intense modes exist that might be experimentally observable. The calculated asymmetric stretching of $\mathrm{CH}_{2}$ is located at $2960 \mathrm{~cm}^{-1}$, while the $\mathrm{CH}_{2}$ scissoring mode is calculated at $1415 \mathrm{~cm}^{-1}$, which correspond well to the experimentally measured peaks at 2957-2960 and $1387 \mathrm{~cm}^{-1}$. The calculated intensities of these two modes are larger than the intensities of the other modes for vinylidene. We note, however, that there is another mode, $\mathrm{CH}_{2}$ rocking at $900 \mathrm{~cm}^{-}$

1 , whose intensity which is more than half of the intensity of the $2960 \mathrm{~cm}^{-1}$ peak. This mode might be observed if the measurements in reference 8 were expanded beyond $900 \mathrm{~cm}^{-1}$, or if their sensitivity were increased.

It is important to note that, if we compare only the frequencies of the vibrational modes, both ethylidene and vinyl also show reasonable matches with the experimentally measured spectra of the intermediates[1]. However, when intensities are also analyzed, this 
promising agreement disappears. For ethylidene, the calculated intensity of the symmetric $\mathrm{CH}_{3}$ stretching mode at $2964 \mathrm{~cm}^{-1}$ is much lower than that for the other four modes. Indeed, the intensity of this peak is only about $1 / 5$ of the most intense peak, $\mathrm{CH}_{3}$ asymmetric stretching at $2863 \mathrm{~cm}^{-1}$. There are another two intense peaks, a mixture of $\mathrm{CH}$ in-plane bending and $\mathrm{CH}_{3}$ symmetric rocking at $1245 \mathrm{~cm}^{-1}$, and $\mathrm{C}-\mathrm{C}$ stretching at $1048 \mathrm{~cm}^{-1}$, which have a similar intensity to the $\mathrm{CH}_{3}$ asymmetric bending at $1403 \mathrm{~cm}^{-1}$. However, none of these peaks were observed in previous experimental studies[8]. In the case of vinyl the calculated result showed that there is an intense peak at $954 \mathrm{~cm}^{-1}$, corresponding to a mixture of $\mathrm{CH}_{2}$ rocking and $\mathrm{CH}$ in-plane bending, that is not observed in the experiments. Further, the calculated intensity for the peak at $1385 \mathrm{~cm}^{-1}$ is weaker than the corresponding experimental intensity.

In order to further distinguish these intermediates, we also simulated the deuterium substituted spectra of these species. The $\mathrm{C}-\mathrm{D}$ stretching modes of $\mathrm{CCD}_{3}, \mathrm{CDCD}_{3}$ and $\mathrm{CCD}_{2}$ are relatively similar to one another. However, there is one mode which belongs to $\mathrm{CCD}_{2}$ that is almost $200 \mathrm{~cm}^{-1}$ away from the other modes belonging to $\mathrm{CDCD}_{3}$ and $\mathrm{CCD}_{3}$. In $\mathrm{CCD}_{2}$, the $\mathrm{C}-\mathrm{C}$ stretching mode is located at $1293 \mathrm{~cm}^{-1}$. The intensity of this mode is also the strongest among all the modes of $\mathrm{CCD}_{2}$. Meanwhile, the non C-D stretching modes for $\mathrm{CDCD}_{3}$ and $\mathrm{CCD}_{3}$ are at least $200 \mathrm{~cm}^{-1}$ lower than the corresponding mode in $\mathrm{CCD}_{2}$, at 1110 $\mathrm{cm}^{-1}$ and $1139 \mathrm{~cm}^{-1}$ respectively. These results strongly suggest that, if one could observe an intermediate peak at around $1293 \mathrm{~cm}^{-1}$ in an experimental spectrum associated with conversion of deuterated ethylene, the importance of the vinylidene intermediate in this reaction would be confirmed.

Finally, we accounted for the impact of coadsorbates on the frequencies and intensities of the deuterated spectra. Since spectra of intermediates in experiments are generally measured with significant amounts of coadsorbed ethylidyne, we calculated the intensities of vinylidene and ethylidene (coverage of 1/9 ML) coadsorbed with 2/9 ML of ethylidyne in a $(3 \times 3)$ unit cell; the corresponding spectra are shown in Fig. 6. In the case of deuterated vinylidene, there is a relatively small influence caused by coadsorbed deuterated ethylidyne. The maximum shift of the frequencies is $2 \mathrm{~cm}^{-1}$ for modes above $500 \mathrm{~cm}^{-1}$. The most intense mode is still C-C stretching at $1293 \mathrm{~cm}^{-1}$. However, in the ethylidene case, the asymmetric $\mathrm{CD}_{3}$ stretching mode shifts by $38 \mathrm{~cm}^{-1}$, to $2006 \mathrm{~cm}^{-1}$. In addition to the modest shift for this mode, the other $\mathrm{CH}$ stretching modes also shift by about $4-17 \mathrm{~cm}^{-1}$. These larger shifts for ethylidene might due to the slightly stronger repulsion between the larger ethylidene molecule and coadsorbed ethylidyne. Nevertheless, our tested coverage effect show that the peak position of vibrational modes are only slightly influenced by co-adsorbed ethylidyne. 


\section{Conclusions}

In this study, we simulated the IR spectra of several important $\mathrm{C}_{2}$ species in the conversion of ethylene to ethylidyne on $\operatorname{Pt}(111)$ by means of periodic density functional calculations. Our calculations reproduced the previous RAIRS spectra of ethylene and ethylidyne on $\mathrm{Pt}(111)$. Furthermore, the simulated spectra of three possible intermediate $\mathrm{C}_{2}$ species, vinyl, vinylidene and ethylidene, suggest that vinylidene might be the experimentally detected intermediate during the ethylidyne formation process on $\operatorname{Pt}(111)$. Vinylidene seemed to have the best match with both the position and intensity of previously observed experimental peaks at $\sim 2960$ and $1387 \mathrm{~cm}^{-1}$. Although the other $\mathrm{C}_{2}$ species also contain vibrational modes which are located close to the experimentally observed frequencies, the intensities are rather weak. Further confirmation of the importance of the vinylidene intermediate could come from deuterium substitution experiments. Due to the slightly stronger $\mathrm{C}-\mathrm{C}$ bonding in $\mathrm{CCD}_{2}$, the C-C stretching mode located at $1293 \mathrm{~cm}^{-1}$, which is almost $200 \mathrm{~cm}^{-1}$ away from all the other modes belonging to $\mathrm{CDCD}_{3}, \mathrm{CCD}_{3}$ and $\mathrm{CDCD}_{2}$. Experimental observation of this feature, combined with the present analysis of vibrational spectra and energetic arguments from previous DFT calculations and kinetic Monte Carlo simulations, would confirm that vinylidene is a key intermediate in this important model chemistry.

\section{Acknowledgments.}

This work was supported by a National Science Foundation Designing Materials to Revolutionize and Engineering our Future program (CBET1437219). Use of the Center for Nanoscale Materials was supported by the U. S. Department of Energy, Office of Science, Office of Basic Energy Sciences, under Contract No: DE-AC02-06CH11357. Computational resources provided by the National Energy Research Scientific Computing Center (NERSC) are gratefully acknowledged. 


\section{References}

[1] Z.-J. Zhao, L. V. Moskaleva, H. A. Aleksandrov, D. Başaran, N. Rösch, J. Phys. Chem. C 114 (2010) 12190-12201.

[2] A. Tilekaratne, J. P. Simonovis, M. F. L. Fagúndez , M. Ebrahimi, F. Zaera, ACS Catal. 2 (2012) 2259-2268.

[3] T. Okada, Y. Kim, M. Trenary, M. Kawai, J. Phys. Chem. C 116 (2012) 18372-18381.

[4] T. Okada, Y. Kim, Y. Sainoo, T. Komeda, M. Trenary, M. Kawai, J. Phys. Chem. Lett. 2 (2011) 2263-2266.

[5] H. Steininger, H, Ibach, S. Lehwald, Surf. Sci. 117 (1982) 685-698.

[6] M. B. Hugenschmidt, P. Dolle, J. Jupille, A. Cassuto, J. Vac. Sci. Technol. A. 7 (1989) 3312-3316.

[7] L. L. Kesmodel, L. H. Dubois, G. A. Somorjai, J. Chem. Phys. 70 (1979) 2180-2188.

[8] R. Deng, E. Herceg, M. Trenary, Surf. Sci. 560, (2004) L195-L201.

[9] F. Zaera, N. Bernstein, J. Am. Chem. Soc. 116 (1994) 4881-4887.

[10] F. Zaera, Langmuir 12 (1996) 88-94.

[11] F. Zaera, C. R. French, J. Am. Chem. Soc. 121 (1999) 2236-2243.

[12] F. Zaera, T. V. W. Janssens, H. Öfner, Surf. Sci. (1996) 362-371.

[13] H. A. Aleksandrov, L. V. Moskaleva, Z.-J. Zhao, D. Başaran, Z.-X. Chen, D. Mei, N. Rösch, J. Catal. 285 (2012) 187-195.

[14] A. T. Anghel, D. J. Wales, S. J. Jenkins, D. A. King, Chem. Phys. Lett. 413 (2005) 289-293.

[15] A. T. Anghel, D. J. Wales, S. J. Jenkins, D. A. King, J. Chem. Phys. 126 (2007) 044710 .

[16] G. Kresse, J. Hafner, Phys. Rev. B 49 (1994) 14251-14269.

[17] G. Kresse, J. Furthmüller, Comput. Mater. Sci. 6 (1996) 15-50.

[18] J. P. Perdew, Y. Wang, Phys. Rev. B 45 (1992) 13244-13249.

[19] P. E. Blöchl, Phys. Rev. B 50 (1994) 17953-17979.

[20] G. Kresse, D. Joubert, Phys. Rev. B 59 (1999) 1758-1775.

[21] M. P. Andersson, P. Uvdal, J. Phys. Chem. A 109 (2005) 2937-2941.

[22] Z.-J. Zhao, Hydrocarbon conversion over transition metal catalysts: A mechanistic study from first-principles calculations, Doctoral Thesis, Technische Universität München, Munich, Germany, 2012.

[23] A. Valcárcel, J. M. Ricart, A. Clotet, F. Illas, A. Markovits, C. Minot, J. Catal. 241 (2006) 115-122.

[24] S. F. Parker, N. A. Marsh, L. M Camus, M. K. Whittlesey, U. A. Jayasooriya, G. J. Kearley, J. Phys. Chem. A 106 (2002) 5797-5802

[25] L. L. Kesmodel, L. H. Dubois, G. A. Somorjai, Chem. Phys. Lett. 56 (1978) 267-271.

[26] Q. Ge, D. A. King, J. Chem. Phys. 110 (1999) 4699-4702.

[27] P. Cremer, C. Stanners, J. W. Niemantsverdriet, Y. R. Shen, G. Somorjai, Surf. Sci. 111 (1995) 111-118.

[28] C. E. Anson, N. Sheppard, D. B. Powell, J. R. Norton, W. Fischer, R. L. Keiter, B. F. G. Johnson, J. Lewis, A. K. Bhattacharrya, S. A. R. Knox, M. L. Turner, J. Am. Chem. Soc. 116 (1994) 3058-3062. 
[29] T. V. W. Janssens, F. Zaera, J. Phys. Chem. 100 (1996) 14118-14129. 
Table 1: Calculated vibrational frequencies (intensities) of di- $\sigma$ ethylene and ethylidyne on $\operatorname{Pt}(111)$ and assignment ${ }^{a}$ of the normal modes

\begin{tabular}{|c|c|c|c|c|c|}
\hline \multicolumn{3}{|c|}{ Ethylidyne $\left(\mathrm{CCH}_{3}\right)$} & \multicolumn{3}{|c|}{ di- $\sigma$ Ethylene $\left(\mathrm{C}_{2} \mathrm{H}_{4}\right)$} \\
\hline DFT(int.) $)^{b}$ & Exp. $^{c}$ & Assignment & DFT(int.) $)^{b}$ & Exp. $^{c}$ & Assignment \\
\hline $2943(2.6)^{d}$ & 2939 & $\mathrm{CH}_{3} v_{\mathrm{a}}$ & $2992(2.5)^{d}$ & & $\mathrm{CH}_{2} v_{\mathrm{a}}$ \\
\hline $2938(2.2)^{d}$ & & $\mathrm{CH}_{3} v_{\mathrm{a}}$ & $2967(3.4)^{d}$ & & $\mathrm{CH}_{2} v_{\mathrm{a}}$ \\
\hline $2871(65)^{d}$ & 2887 & $\mathrm{CH}_{3} v_{\mathrm{s}}$ & $2913(100)^{d}$ & 2908 & $\mathrm{CH}_{2} v_{\mathrm{s}}$ \\
\hline & & & $2905(2.6)^{d}$ & & $\mathrm{CH}_{2} v_{\mathrm{s}}$ \\
\hline $1407(0.1)$ & 1444 & $\mathrm{CH}_{3} \delta_{\mathrm{a}}$ & $1419(6.6)$ & 1416 & $\mathrm{CH}_{2} \delta$ \\
\hline $1406(0.1)$ & & $\mathrm{CH}_{3} \rho_{\mathrm{a}}$ & $1386(0.2)$ & & $\mathrm{CH}_{2} \delta$ \\
\hline $1325(100)$ & 1340 & $\mathrm{CH}_{3} \delta_{\mathrm{s}}$ & $1180(0)$ & & $\mathrm{CH}_{2} \rho$ \\
\hline $1107(66)$ & 1124 & $\mathrm{CC} v$ & $1040(0.8)$ & & $\mathrm{CH}_{2} \omega$ \\
\hline $962(0.1)$ & 975 & $\mathrm{CH}_{3} \rho_{\mathrm{s}}$ & $1036(21)$ & 1042 & $\mathrm{CC} v / \mathrm{CH}_{2} \omega$ \\
\hline $960(0.1)$ & & $\mathrm{CH}_{3} \rho_{\mathrm{s}}$ & $981(20)$ & 995 & $\mathrm{CH}_{2} \omega / \mathrm{CC} v$ \\
\hline & & & $935(0.3)$ & & $\mathrm{CH}_{2} \rho$ \\
\hline & & & $782(0.1)$ & & $\mathrm{CH}_{2} \tau$ \\
\hline $460(0)$ & & $\mathrm{Pt}_{3} \mathrm{C} v_{\mathrm{a}}$ & $638(0)$ & & $\mathrm{CH}_{2} \tau$ \\
\hline $459(0)$ & & $\mathrm{Pt}_{3} \mathrm{C} v_{\mathrm{a}}$ & $547(0)$ & & $\mathrm{PtC} v_{\mathrm{a}}$ \\
\hline $404(2.3)$ & & $\mathrm{Pt}_{3} \mathrm{C} v_{\mathrm{s}}$ & $449(6.7)$ & & $\mathrm{PtC} v_{\mathrm{s}}$ \\
\hline $190(0)$ & & $\mathrm{CH}_{3} \tau$ & 194(0) & & $\operatorname{PtC} \delta_{\text {ip }}$ \\
\hline $157(0)$ & & FT / FR & $141(0)$ & & $\operatorname{PtC} \delta_{\text {op }}$ \\
\hline $155(0)$ & & FT / FR & 119(0) & & $\operatorname{PtC} \delta_{\text {op }}$ \\
\hline
\end{tabular}

a Notations used: $v$, stretching; $\delta$, bending; $\tau$, twisting; $\omega$, wagging; $\rho$, rocking; a, asymmetric; s, symmetric; ip, in-plane; op, out-of-plane; FR, frustrated rotation; FT, frustrated translation.

${ }^{b}$ Unit of frequency is $\mathrm{cm}^{-1}$. Intensities were shown in brackets and scaled (\%) by the strongest one of each species.

${ }^{c}$ Ref 8 .

${ }^{d}$ Scalled by 0.976 
Table 2: Calculated vibrational frequencies (intensity) of relevant $\mathrm{C}_{2} \mathrm{H}_{n}$ intermediates ( $\mathrm{n}=$ 2-4) on $\mathrm{Pt}(111)$ and assignment ${ }^{a}$ of the normal modes

\begin{tabular}{|c|c|c|c|c|c|}
\hline \multicolumn{2}{|c|}{ Ethylidene $\left(\mathrm{CHCH}_{3}\right)$} & \multicolumn{2}{|c|}{ Vinyl $\left(\mathrm{CHCH}_{2}\right)$} & \multicolumn{2}{|c|}{ Vinylidene $\left(\mathrm{CCH}_{2}\right)$} \\
\hline DFT(int.) $^{b}$ & Assignment & DFT(int.) ${ }^{b}$ & Assignment & DFT(int.) ${ }^{b}$ & Assignment \\
\hline $2964(18)^{c}$ & $\mathrm{CH}_{3} v_{\mathrm{a}}$ & $2942(4.6)^{c}$ & $\mathrm{CH}_{2} v_{\mathrm{a}}$ & $3046(4.0)^{c}$ & $\mathrm{CH}_{2} \mathrm{v}_{\mathrm{a}}$ \\
\hline $2918(0.4)^{c}$ & $\mathrm{CH} v / \mathrm{CH}_{3} v_{\mathrm{a}}$ & $2932(40)^{c}$ & $\mathrm{CH} v$ & $2960(35)^{c}$ & $\mathrm{CH}_{2} v_{\mathrm{s}}$ \\
\hline $2910(4.9)^{c}$ & $\mathrm{CH}_{3} v_{\mathrm{a}} / \mathrm{CH} v$ & $2880(100)^{c}$ & $\mathrm{CH}_{2} v_{\mathrm{s}}$ & & \\
\hline $2863(100)^{c}$ & $\mathrm{CH}_{3} v_{\mathrm{s}}$ & & & & \\
\hline $1404(1.4)$ & $\mathrm{CH}_{3} \delta_{\mathrm{a}}$ & $1385(17)$ & $\mathrm{CH}_{2} \delta$ & $1415(100)$ & $\mathrm{CH}_{2} \delta$ \\
\hline $1403(53)$ & $\mathrm{CH}_{3} \delta_{\mathrm{a}}$ & $1107(14)$ & $\mathrm{CH} \delta_{\mathrm{ip}} / \mathrm{CC} v$ & $1260(5.1)$ & $\mathrm{CC} v$ \\
\hline $1326(22)$ & $\mathrm{CH}_{3} \delta_{\mathrm{s}}$ & $1062(15)$ & $\mathrm{CC} v / \mathrm{CH} \delta_{\text {ip }}$ & $979(0.1)$ & $\mathrm{CH}_{2} \rho$ \\
\hline $1245(57)$ & $\mathrm{CH} \delta_{\mathrm{ip}} / \mathrm{CH}_{3} \rho_{\mathrm{s}}$ & $1010(0)$ & $\mathrm{CH}_{2} \rho$ & $900(21)$ & $\mathrm{CH}_{2} \omega$ \\
\hline $1048(52)$ & $\mathrm{CC} v$ & $954(59)$ & $\mathrm{CH}_{2} \omega$ & 694(0) & $\mathrm{CH}_{2} \tau$ \\
\hline $947(0.3)$ & $\mathrm{CH}_{3} \rho_{\mathrm{a}} / \mathrm{CH} \delta_{\mathrm{op}}$ & $730(0)$ & $\mathrm{CH} \delta_{\mathrm{op}} / \mathrm{CH}_{2} \tau$ & & \\
\hline $935(14)$ & $\mathrm{CH}_{3} \rho_{\mathrm{s}} / \mathrm{CH} \delta_{\mathrm{ip}}$ & $661(0)$ & $\mathrm{CH}_{2} \tau / \mathrm{CH} \delta_{\mathrm{op}}$ & & \\
\hline $790(0)$ & $\mathrm{CH} \delta_{\mathrm{op}}$ & & & & \\
\hline 493(0.4) & $\mathrm{Pt}_{2} \mathrm{C} v_{\mathrm{s}}$ & $569(0)$ & $\mathrm{Pt}_{3} \mathrm{C}_{2} v_{\mathrm{a}}$ & $518(0)$ & $\mathrm{Pt}_{3} \mathrm{C} v_{\mathrm{a}}$ \\
\hline $372(0)$ & $\mathrm{Pt}_{2} \mathrm{C} v_{\mathrm{a}}$ & $506(4.3)$ & $\mathrm{Pt}_{3} \mathrm{C}_{2} v_{\mathrm{s}}$ & $469(0.1)$ & $\mathrm{Pt}_{3} \mathrm{C} v_{\mathrm{s}}$ \\
\hline $279(0)$ & $\mathrm{Pt}_{2} \mathrm{C} \delta$ & $378(0)$ & $\mathrm{Pt}_{3} \mathrm{C}_{2} \delta_{\mathrm{op}}$ & $410(6.0)$ & FR \\
\hline $163(0)$ & $\mathrm{CH}_{3} \tau$ & $252(0)$ & $\mathrm{Pt}_{3} \mathrm{C}_{2} \delta_{\mathrm{ip}}$ & $263(2.6)$ & $\mathrm{PtC}^{(\mathrm{H} 2)} v$ \\
\hline $107(0)$ & FR & $222(0)$ & $\mathrm{Pt}_{3} \mathrm{C}_{2} \delta_{\mathrm{op}}$ & 212(0) & $\mathrm{PtC}^{(\mathrm{H} 2)} \delta$ \\
\hline $94(0.1)$ & FR & & & & \\
\hline
\end{tabular}

$a$ Notations used: $v$, stretching; $\delta$, bending; $\tau$, twisting; $\omega$, wagging; $\rho$, rocking; a, asymmetric; s, symmetric; ip, in-plane; op, out-of-plane; FR, frustrated rotation.

${ }^{b}$ Unit of frequency is $\mathrm{cm}^{-1}$. Intensities are shown in brackets and scaled (\%) by the strongest intensity mode of each species.

${ }^{c}$ Scalled by 0.976 
Table 3: Calculated vibrational frequencies (intensity) of deuterium substituted di- $\sigma$ ethylene and ethylidyne on $\operatorname{Pt}(111)$ and assignment ${ }^{a}$ of the normal modes

\begin{tabular}{|c|c|c|c|c|c|}
\hline \multicolumn{3}{|c|}{ Ethylidyne $\left(\mathrm{CCD}_{3}\right)$} & \multicolumn{3}{|c|}{ di- $\sigma$ ethylene $\left(\mathrm{C}_{2} \mathrm{D}_{4}\right)$} \\
\hline DFT(int.) $)^{b}$ & Exp. $^{\mathrm{c}}$ & Assignment & DFT(int.) ${ }^{b}$ & Exp. $^{c}$ & Assignment \\
\hline $2230(0.5)$ & & $\mathrm{CD}_{3} v_{\mathrm{a}}$ & $2275(1.8)$ & & $\mathrm{CD}_{2} v_{\mathrm{a}}$ \\
\hline $2226(0.5)$ & 2220 & $\mathrm{CD}_{3} v_{\mathrm{a}}$ & $2259(3.1)$ & 2250 & $\mathrm{CD}_{2} v_{\mathrm{a}}$ \\
\hline \multirow[t]{2}{*}{$2109(16)$} & 2080 & $\mathrm{CD}_{3} v_{\mathrm{s}}$ & $2167(100)$ & 2150 & $\mathrm{CD}_{2} v_{\mathrm{s}}$ \\
\hline & & & 2152(1.9) & & $\mathrm{CD}_{2} v_{\mathrm{s}}$ \\
\hline 1139(100) & 1160 & $\mathrm{CC} v$ & $1132(72)$ & 1150 & $\mathrm{CC} v$ \\
\hline $1013(0)$ & 1030 & $\mathrm{CD}_{3} \delta_{\mathrm{a}}$ & $1022(0.1)$ & & $\mathrm{CD}_{2} \delta$ \\
\hline $1012(0)$ & & $\mathrm{CD}_{3} \rho_{\mathrm{a}}$ & 923(0) & & $\mathrm{CD}_{2} \rho$ \\
\hline $965(1.2)$ & 990 & $\mathrm{CD}_{3} \delta_{\mathrm{s}}$ & $882(53)$ & 900 & $\mathrm{CD}_{2} \delta$ \\
\hline $773(0.1)$ & 790 & $\mathrm{CD}_{3} \rho_{\mathrm{s}}$ & $836(0.5)$ & & $\mathrm{CD}_{2} \omega$ \\
\hline $772(0.1)$ & & $\mathrm{CD}_{3} \rho_{\mathrm{s}}$ & $734(2.1)$ & 740 & $\mathrm{CD}_{2} \omega$ \\
\hline $436(0)$ & & $\mathrm{Pt}_{3} \mathrm{C} v_{\mathrm{a}}$ & $661(0.3)$ & & $\mathrm{CD}_{2} \rho$ \\
\hline $435(0)$ & & $\mathrm{Pt}_{3} \mathrm{C} v_{\mathrm{a}}$ & $580(0.1)$ & & $\mathrm{CD}_{2} \tau$ \\
\hline $376(1.8)$ & & $\mathrm{Pt}_{3} \mathrm{C} v_{\mathrm{s}}$ & $484(0.1)$ & & $\mathrm{PtC} v_{\mathrm{a}}$ \\
\hline 137(0) & & FT / FR & $472(0.1)$ & & $\mathrm{CD}_{2} \tau$ \\
\hline $135(0)$ & & FT / FR & $429(18)$ & & $\mathrm{PtC} v_{\mathrm{s}}$ \\
\hline \multirow[t]{3}{*}{$134(0)$} & & $\mathrm{CD}_{3} \tau$ & $181(0.1)$ & & $\mathrm{PtC} \delta_{\mathrm{ip}}$ \\
\hline & & & $116(0.1)$ & & $\operatorname{PtC} \delta_{\mathrm{op}}$ \\
\hline & & & $108(0.1)$ & & $\operatorname{PtC} \delta_{\mathrm{op}}$ \\
\hline
\end{tabular}

\footnotetext{
${ }^{a}$ Notations used: $v$, stretching; $\delta$, bending; $\tau$, twisting; $\omega$, wagging; $\rho$, rocking; a, asymmetric; s, symmetric; ip, in-plane; op, out-of-plane; FR, frustrated rotation; FT, frustrated translation.

${ }^{b}$ Unit of frequency is $\mathrm{cm}^{-1}$. Intensities are shown in brackets and scaled (\%) by the strongest intensity mode of each species.

${ }^{c}$ Ref 5.
} 
Table 4: Calculated vibrational frequencies (intensity) of relevant $C_{2} D_{n}$ intermediates ( $n=$ 2-4) on $\mathrm{Pt}(111)$ and assignment ${ }^{a}$ of the normal modes

\begin{tabular}{|c|c|c|c|c|c|}
\hline \multicolumn{2}{|c|}{ Ethylidene $\left(\mathrm{CDCD}_{3}\right)$} & \multicolumn{2}{|l|}{ Vinyl $\left(\mathrm{CDCD}_{2}\right)$} & \multicolumn{2}{|c|}{ Vinylidene $\left(\mathrm{CCD}_{2}\right)$} \\
\hline DFT(int.) ${ }^{b}$ & Assignment & DFT(int.) ${ }^{b}$ & Assignment & DFT(int.) ${ }^{b}$ & Assignment \\
\hline $2244(14)$ & $\mathrm{CD} v / \mathrm{CD}_{3} v_{\mathrm{a}}$ & $2235(2.5)$ & $\mathrm{CD}_{2} v_{\mathrm{a}}$ & $2321(2.1)$ & $\mathrm{CD}_{2} v_{\mathrm{a}}$ \\
\hline $2203(2.6)$ & $\mathrm{CD}_{3} v_{\mathrm{a}}$ & $2207(33)$ & $\mathrm{CD} v$ & $2200(16)$ & $\mathrm{CD}_{2} v_{\mathrm{s}}$ \\
\hline 2192(0.5) & $\mathrm{CD} v / \mathrm{CD}_{3} v_{\mathrm{a}}$ & $2136(68)$ & $\mathrm{CD}_{2} v_{\mathrm{s}}$ & $1293(100)$ & $\mathrm{CC} v$ \\
\hline $2106(41)$ & $\mathrm{CD}_{3} v_{\mathrm{s}}$ & $1115(100)$ & $\mathrm{CC} v$ & $995(22))$ & $\mathrm{CD}_{2} \delta$ \\
\hline $1110(80)$ & $\mathrm{CC} v$ & $972(4.8)$ & $\mathrm{CD}_{2} \delta$ & $800(0.2)$ & $\mathrm{CD}_{2} \rho$ \\
\hline $1011(0.2)$ & $\mathrm{CD}_{3} \delta_{\mathrm{a}}$ & $865(0.2)$ & $\mathrm{CD}_{2} \omega / \mathrm{CD} \delta_{\text {ip }}$ & $694(14)$ & $\mathrm{CD}_{2} \omega$ \\
\hline $1009(100)$ & $\mathrm{CD}_{3} \delta_{\mathrm{s}} / \mathrm{CD} \delta_{\mathrm{ip}}$ & $787(0)$ & $\mathrm{CD}_{2} \rho$ & $513(0)$ & $\mathrm{CD}_{2} \tau$ \\
\hline $994(4.5)$ & $\mathrm{CD} \delta_{\mathrm{ip}} / \mathrm{CD}_{3} \delta_{\mathrm{s}}$ & 694(39) & $\mathrm{CD} \delta_{\mathrm{ip}} / \mathrm{CD}_{2} \omega$ & $465(0)$ & $\mathrm{Pt}_{3} \mathrm{C} v_{\mathrm{a}}$ \\
\hline $903(2.1)$ & $\mathrm{CCD} \delta$ & $537(0)$ & $\mathrm{CD} \delta_{\mathrm{op}} / \mathrm{CD}_{2} \tau$ & $460(0.3)$ & $\mathrm{Pt}_{3} \mathrm{C} v_{\mathrm{s}}$ \\
\hline $766(0)$ & $\mathrm{CD}_{3} \rho_{\mathrm{a}} / \mathrm{CD} \delta_{\mathrm{op}}$ & $516(2.3)$ & $\mathrm{Pt}_{2} \mathrm{C}^{(\mathrm{H})} v_{\mathrm{s}}$ & $395(10)$ & FR \\
\hline $700(2.8)$ & $\mathrm{CD}_{3} \rho_{\mathrm{s}} / \mathrm{CD} \delta_{\mathrm{ip}}$ & 477(0) & $\mathrm{CD} \delta_{\mathrm{op}} / \mathrm{CD}_{2} \tau$ & $243(4.3)$ & $\mathrm{PtC}^{(\mathrm{H} 2)} v$ \\
\hline $574(0.1)$ & $\mathrm{CD} \delta_{\mathrm{op}} / \mathrm{CD}_{3} \rho_{\mathrm{a}}$ & $470(7.6)$ & $\mathrm{PtC}^{(\mathrm{H} 2)} v$ & $186(0)$ & $\mathrm{PtC}^{(\mathrm{H} 2)} \delta$ \\
\hline $447(0.3)$ & $\mathrm{Pt}_{2} \mathrm{C} v_{\mathrm{s}}$ & $348(0)$ & $\mathrm{Pt}_{2} \mathrm{C}^{(\mathrm{H})} v_{\mathrm{a}}$ & & \\
\hline $342(0.1)$ & $\mathrm{Pt}_{2} \mathrm{C} v_{\mathrm{a}}$ & $237(0)$ & $\mathrm{Pt}_{3} \mathrm{C}_{2} \delta_{\text {ip }}$ & & \\
\hline $252(0.3)$ & $\mathrm{Pt}_{2} \mathrm{C} \delta$ & $197(0)$ & $\mathrm{Pt}_{3} \mathrm{C}_{2} \delta_{\mathrm{op}}$ & & \\
\hline $129(0.1)$ & $\mathrm{CD}_{3} \tau$ & & & & \\
\hline $84(0.2)$ & FR & & & & \\
\hline $83(0.1)$ & FR & & & & \\
\hline
\end{tabular}

a Notations used: $v$, stretching; $\delta$, bending; $\tau$, twisting; $\omega$, wagging; $\rho$, rocking; a, asymmetric; s, symmetric; ip, in-plane; op, out-of-plane; FR, frustrated rotation.

${ }^{b}$ Unit of frequency is $\mathrm{cm}^{-1}$. Intensities are shown in brackets and scaled (\%) by the strongest intensity mode of each species. 


\section{Figure captions}

Figure 1. Optimized structures of ethylidyne $(\mathrm{CCH} 3)$; di- $\sigma$ ethylene $\left(\mathrm{C}_{2} \mathrm{H}_{4}\right)$; vinyl $\left(\mathrm{CHCH}_{2}\right)$; ethylidene $\left(\mathrm{CHCH}_{3}\right)$, and vinylidene $\left(\mathrm{CCH}_{2}\right)$.

Figure 2. Simulated IR spectra of stable surface species on $\mathrm{Pt}\left(111\right.$ ): (a) ethylidyne $\mathrm{CCH}_{3}$ at $1 / 3 \mathrm{ML}$ and (b) di- $\sigma$ ethylene $\mathrm{C}_{2} \mathrm{H}_{4}$ at 1/4 ML.

Figure 3. Simulated IR spectra of surface intermediates with 1/3 ML coverage on $\operatorname{Pt}(111)$ : (a) vinyl $\mathrm{CHCH}_{2}$; (b) vinylidene $\mathrm{CCH}_{2}$; and (c) ethylidene $\mathrm{CHCH}_{3}$.

Figure 4. Simulated IR spectra of deuterium substituted surface species on $\operatorname{Pt}(111)$ : (a) ethylidyne $\mathrm{CCD}_{3}$ at $1 / 3 \mathrm{ML}$ and (b) di- $\sigma$ ethylene $\mathrm{C}_{2} \mathrm{D}_{4}$ at $1 / 4 \mathrm{ML}$.

Figure 5 Simulated IR spectra of surface intermediates with 1/3 ML coverage on $\mathrm{Pt}(111)$ : (a) vinyl $\mathrm{CDCD}_{2}$; (b) vinylidene $\mathrm{CCD}_{2}$; and (c) ethylidene $\mathrm{CDCD}_{3}$.

Figure 6 Simulated IR spectra of deuterium substituted surface species and intermediates on $\mathrm{Pt}$ (111): (a) 1/9 $\mathrm{ML}$ vinylidene $\mathrm{CCD}_{2}$ (co-adsorbed with 2/9 $\mathrm{ML}$ ethylidyne $\mathrm{CCD}_{3}$ ), and (b) 1/9 ML ethylidene $\mathrm{CDCD}_{3}$ (co-adsorbed with 2/9 ML ethylidyne $\mathrm{CCH}_{3}$ ). 


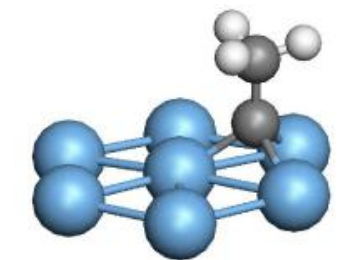

ethylidyne

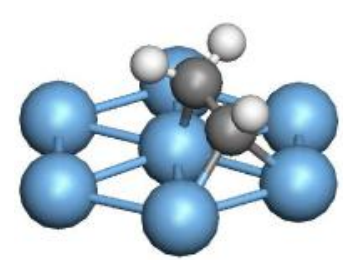

vinyl

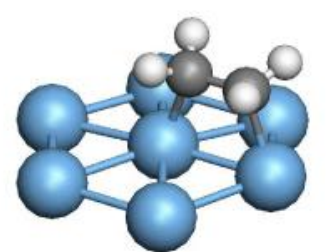

di-ethylene

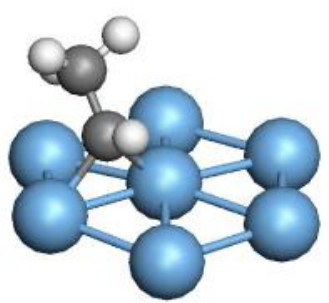

ethylidene

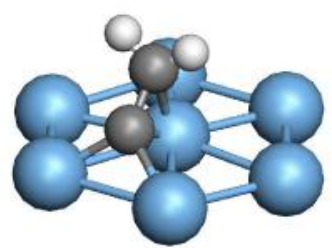

vinylidene

Figure 1. Optimized structures of ethylidyne $(\mathrm{CCH} 3)$; di- $\sigma$ ethylene $\left(\mathrm{C}_{2} \mathrm{H}_{4}\right)$; vinyl $\left(\mathrm{CHCH}_{2}\right)$; ethylidene $\left(\mathrm{CHCH}_{3}\right)$, and vinylidene $\left(\mathrm{CCH}_{2}\right)$. 

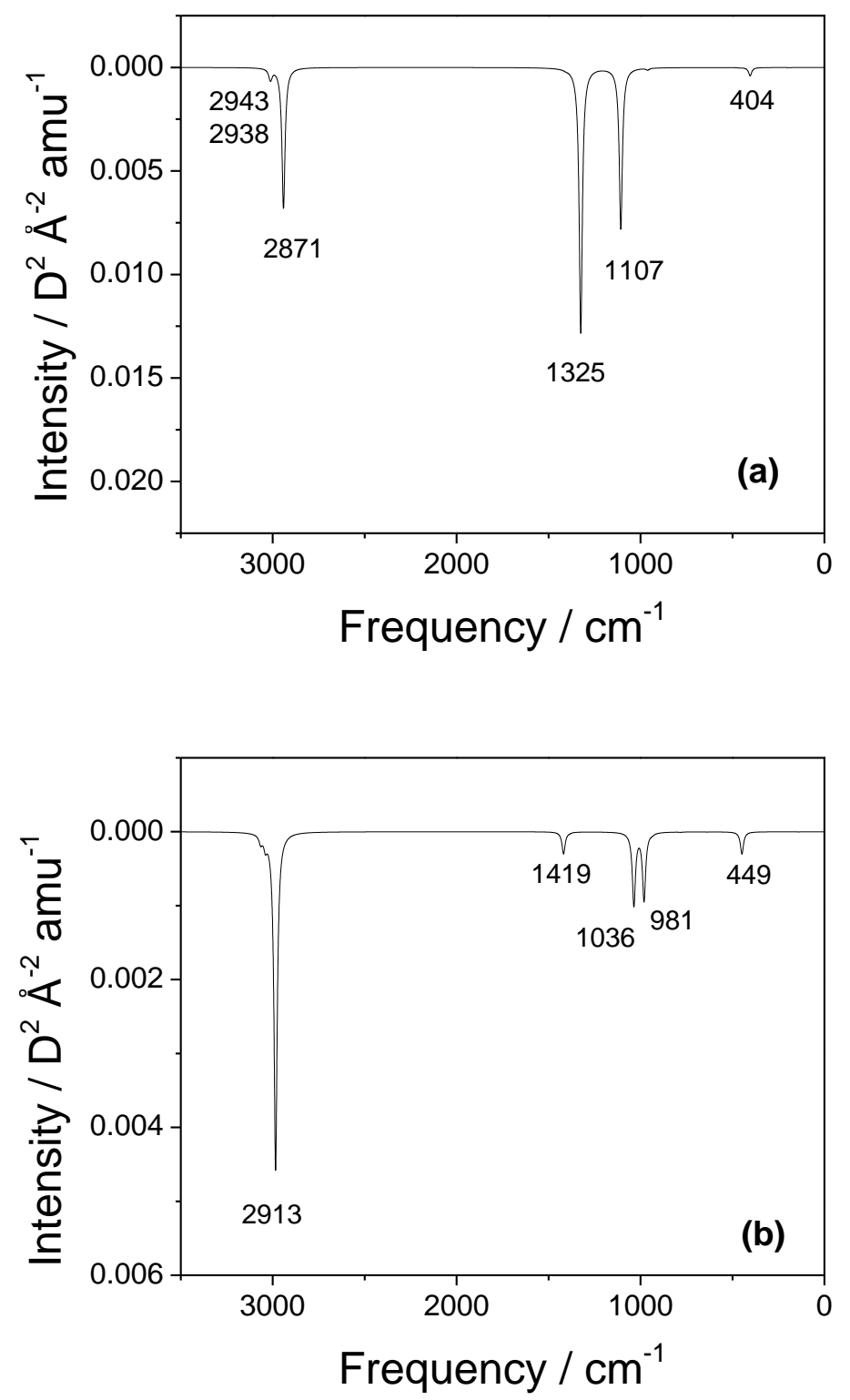

Figure 2 Simulated IR spectra of stable surface species on $\mathrm{Pt}(111)$ : (a) ethylidyne $\mathrm{CCH}_{3}$ at $1 / 3 \mathrm{ML}$ and (b) di- $\sigma$ ethylene $\mathrm{C}_{2} \mathrm{H}_{4}$ at $1 / 4 \mathrm{ML}$. 

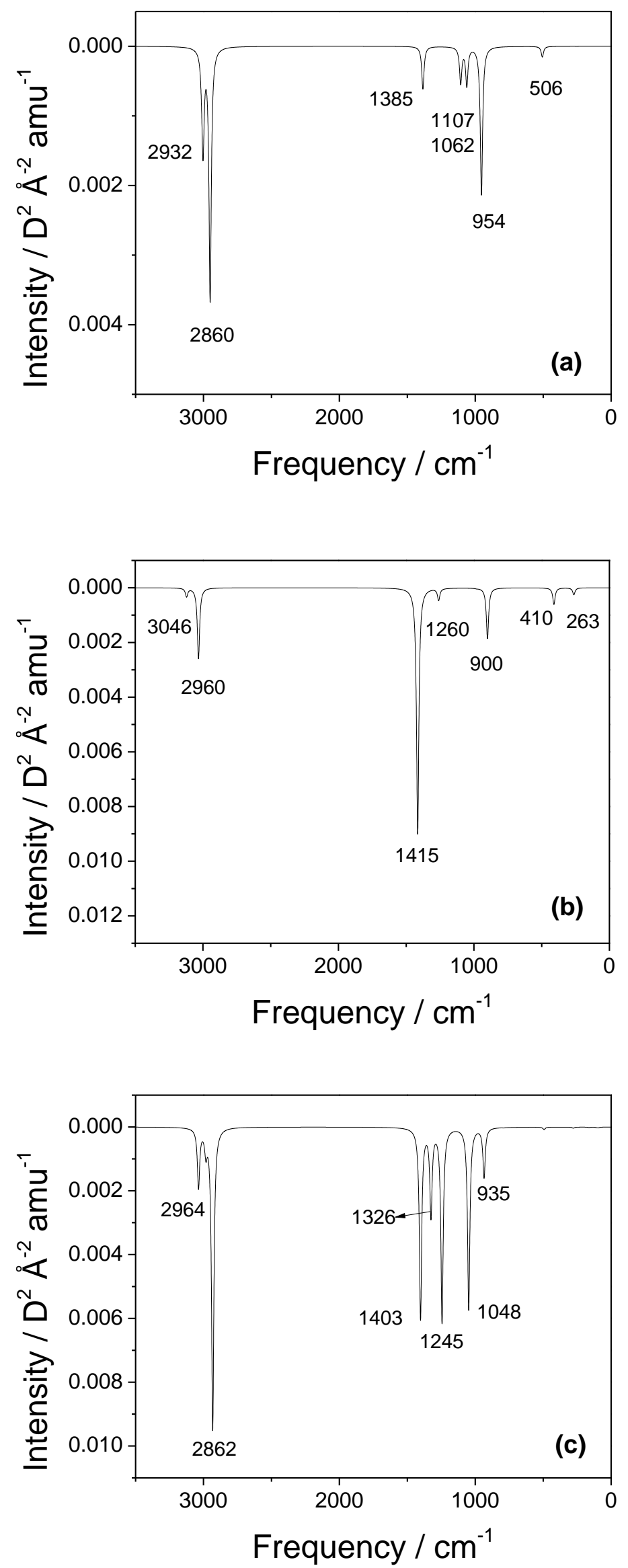

Figure 3 Simulated IR spectra of surface intermediates with $1 / 3 \mathrm{ML}$ coverage on $\mathrm{Pt}(111)$ : (a) vinyl $\mathrm{CHCH}_{2}$; (b) vinylidene $\mathrm{CCH}_{2}$; and (c) ethylidene $\mathrm{CHCH}_{3}$. 

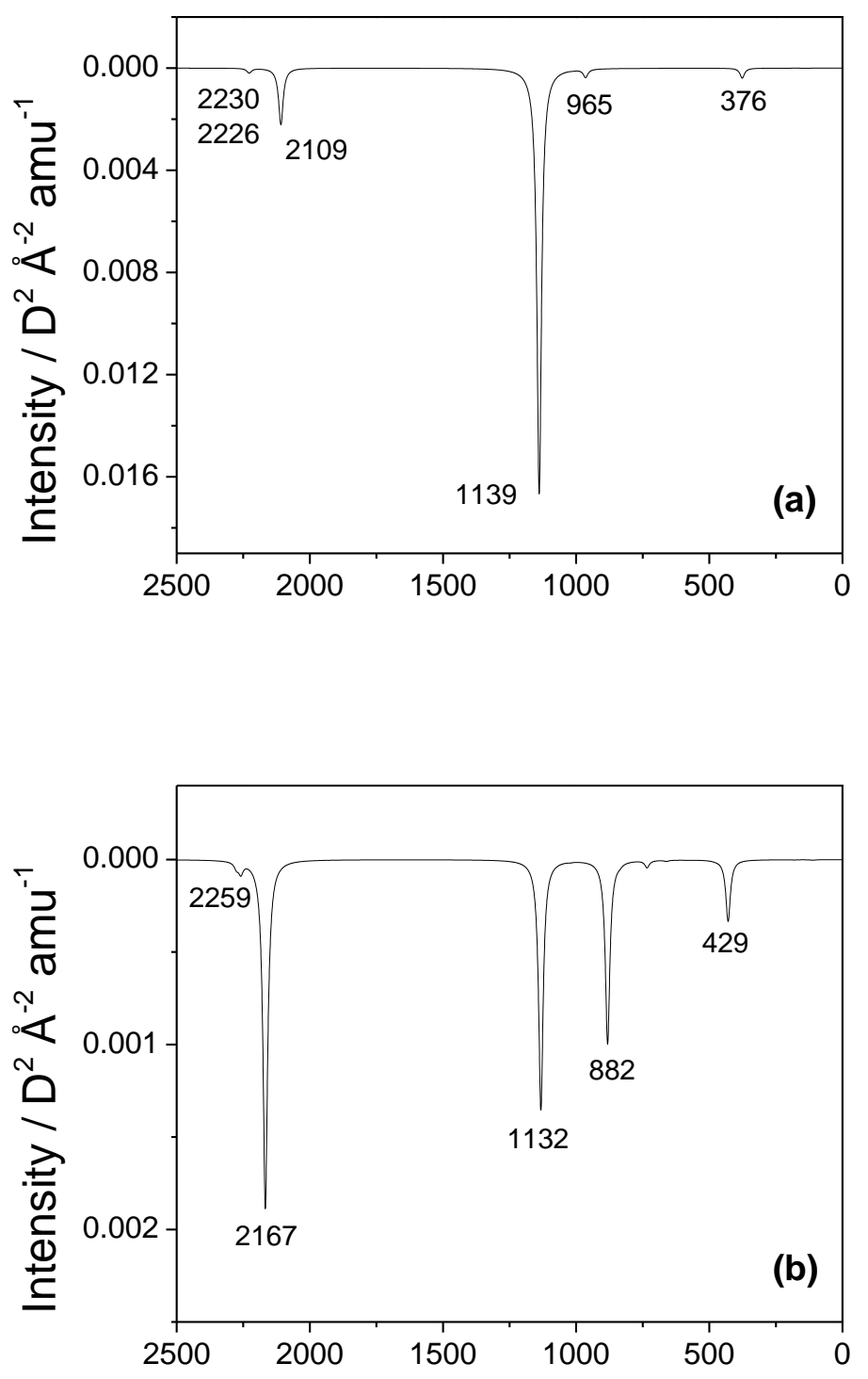

Figure 4 Simulated IR spectra of deuterium substituted surface species on $\operatorname{Pt}(111)$ : (a) ethylidyne $\mathrm{CCD}_{3}$ at $1 / 3 \mathrm{ML}$ and (b) di- $\sigma$ ethylene $\mathrm{C}_{2} \mathrm{D}_{4}$ at $1 / 4 \mathrm{ML}$. 

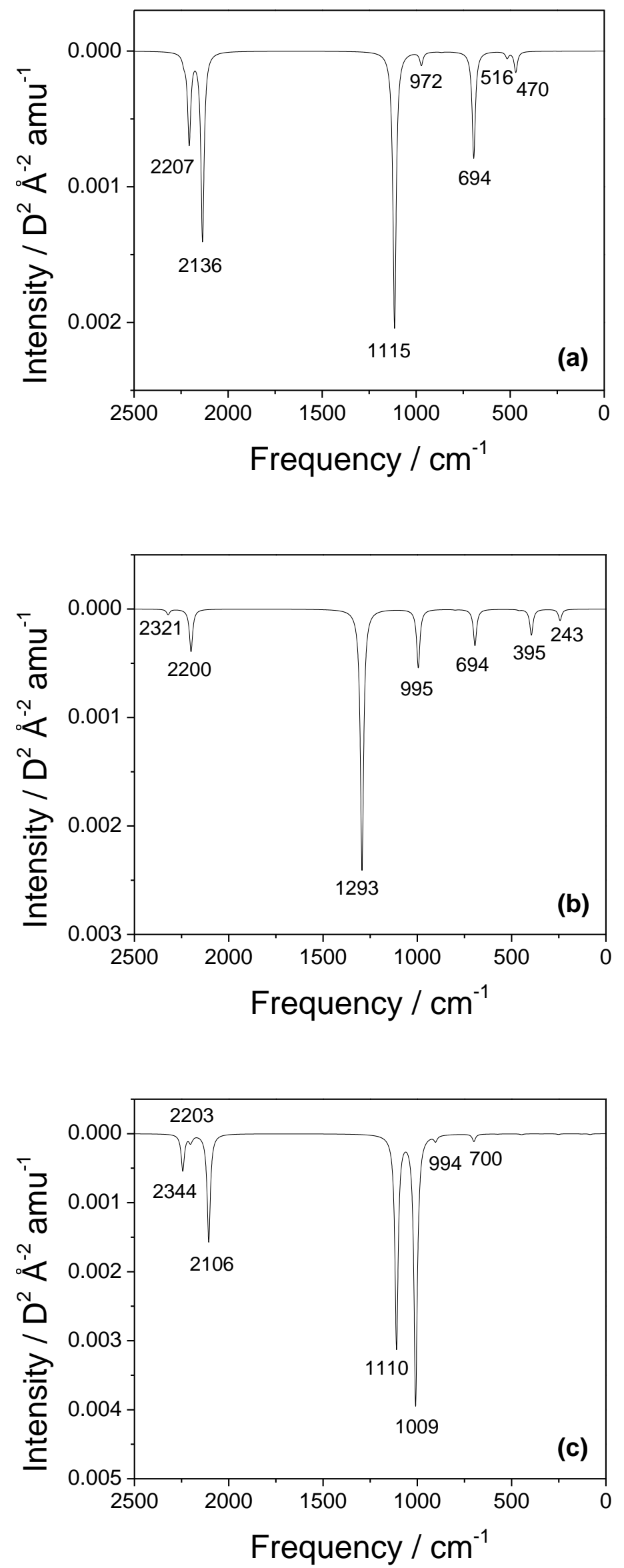

Figure 5 Simulated IR spectra of surface intermediates with $1 / 3$ ML coverage on $\operatorname{Pt}(111)$ : (a) vinyl $\mathrm{CDCD}_{2}$; (b) vinylidene $\mathrm{CCD}_{2}$; and (c) ethylidene $\mathrm{CDCD}_{3}$. 

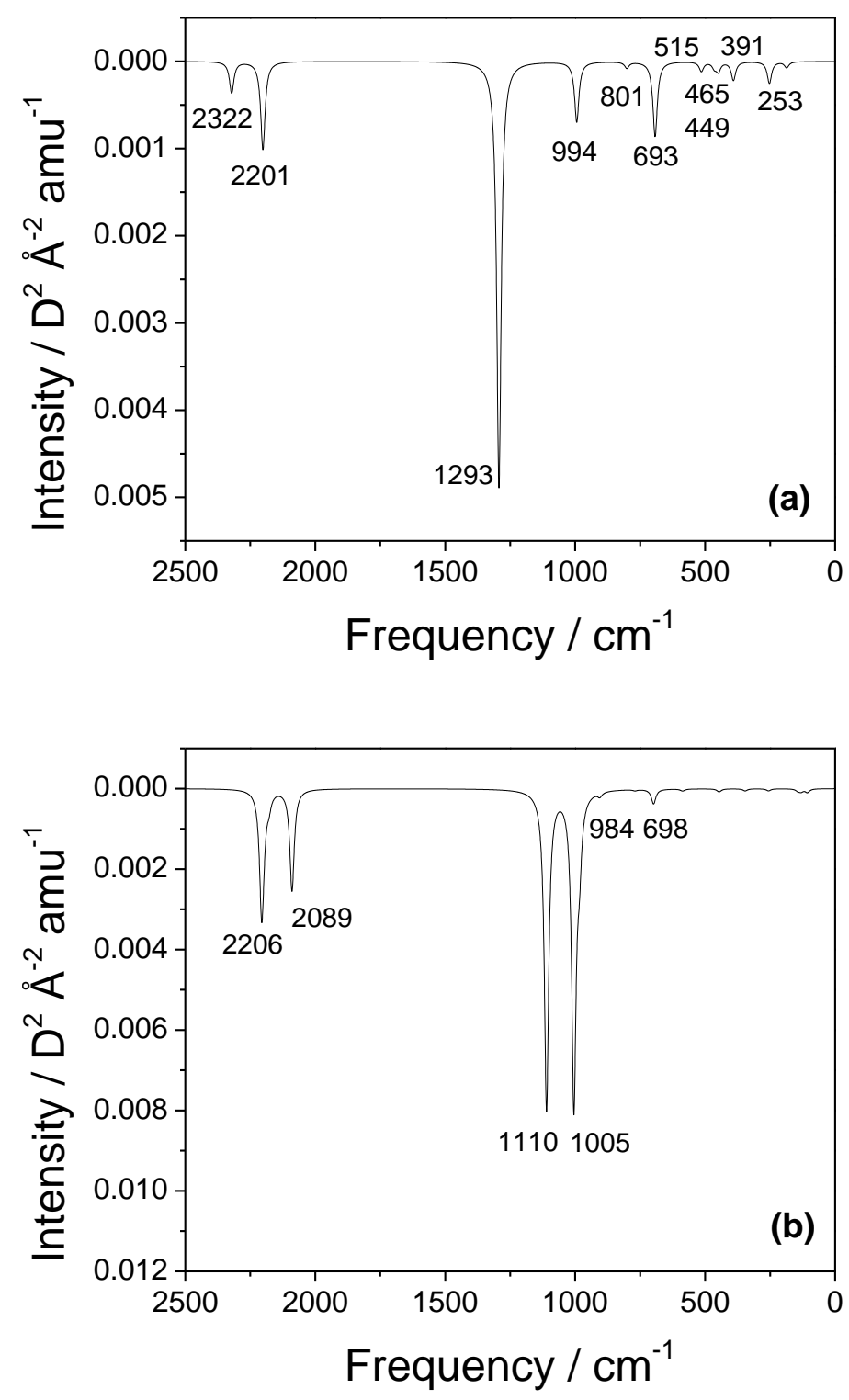

Figure 6 Simulated IR spectra of deuterium substituted surface species and intermediates on $\mathrm{Pt}(111)$ : (a) 1/9 ML vinylidene $\mathrm{CCD}_{2}$ (co-adsorbed with $2 / 9 \mathrm{ML}$ ethylidyne $\mathrm{CCD}_{3}$ ), and (b) 1/9 ML ethylidene $\mathrm{CDCD}_{3}$ (co-adsorbed with 2/9 ML ethylidyne $\mathrm{CCH}_{3}$ ). 